\title{
Kahoot!'s contribution to immediate learning feedback for anatomy students
}

\author{
Daniel P.M. Barros ${ }^{1}$, Diego A.C. Santana ${ }^{1}$, Thaíse K.L. Costa ${ }^{2}$, Ana K.F.T.C. Pereira ${ }^{3}$, Amira R.C. Medeiros ${ }^{3}$ \\ ${ }^{1}$ Medical Sciences Center, Federal University of Paraiba, João Pessoa, Brazil \\ ${ }^{2}$ Department of Exact Sciences, Federal University of Paraiba, Rio Tinto, Brazil \\ ${ }^{3}$ Department of Morphology, Federal University of Paraiba, João Pessoa, Brazil
}

\section{SUMMARY}

Kahoot! is a popular game-based learning platform. This study aims to investigate whether there is a relationship between Kahoot! score and student's grade in the traditional examination (GTE), and to understand their perception about the use of this platform. A cross-sectional study was developed in the Human Anatomy course, which is divided into 5 topics of systemic anatomy (TSA). 5-question quizzes about the taught subject were given at the end of $66.7 \%$ of the lectures. 53 students who participated in at least one of the quizzes were included. In each TSA, students were subjected to a traditional examination (GTE, scale 0-10) and the mean of Kahoot! scores (MKS, scale 0-6000) was calculated, totalizing 190 independent observations. An opinion questionnaire was given at the course's end. Spearman's test analyzed the correlation between MKS and GTE; area under the ROC curve (AUC) evaluated MKS's ability to predict GTE; chi-square test verified the association between the categorical variables. There was a positive moderate correlation between MKS and GTE (rho=0.43, $\mathrm{p}<0.001$ ). MKS performed regularly to predict GTE $\geq 9$ (AUC $=0.734) .67 .8 \%$ of the students in the $\mathrm{MKS} \geq 3000$ group obtained GTE $\geq 9$, versus only $28.0 \%$ in the $\mathrm{MKS}<3000$ group $(\mathrm{p}<0.001)$. Amongst the $<20$-year-old students, $83.3 \%$ agreed that Kahoot! was important to motivate them as they studied, versus $52.4 \%$ in the $\geq 20$-year-old group ( $\mathrm{p}=0.041$ ). Kahoot!'s score can provide immediate feedback about the student's learning process, and it serves as a parameter to predict their final performance. The motivation to use Kahoot! can be influenced by the students' age.

Key words: Kahoot - Game-based learning Anatomy - Teaching - Active learning

\section{INTRODUCTION}

Anatomy is an essential subject for medical training, as it introduces students to the medical language and the study of pathophysiology (Shaffer, 2004). Clinical doctors or surgeons use anatomical knowledge to carry out a good physical examination of the patient, form diagnostic hypotheses, interpret medical imaging and communicate the findings to the patient and other professionals involved in care (Turney, 2007). However, the teaching of Human Anatomy has been facing some challenges over the last decades, such as the progressive reduction of available

Submitted: November 8, 2021. Accepted: December 9, 2021 
time, the large amount of content, the increase in the number of students and the difficulty of access to cadaveric dissection (Guimarães et al., 2017). In addition, the new generation of students has demands such as connectivity, practical application of knowledge and innovation in the teaching-learning process (Ruzycki et al., 2019), in contrast to the shortage of anatomy professors in the labor market (Wilson et al., 2020). In the last few years, the perspective that the best way to deal with these difficulties is by combining several pedagogical resources that complement one another has grown, ranging from traditional dissection to new methods of active learning (Estai and Bunt, 2016).

Several active learning techniques have been used to overcome the challenges inherent in the teaching-learning process of anatomy, such as team-based learning, case-based learning and game-based learning (Singh et al., 2019; Aktekin et al., 2018; Zumwalt et al., 2010; Nieder et al., 2005). Associated with these new pedagogical practices, technological advances have shown that applications for smartphones can be useful tools in medical education (Payne et al., 2012; Fan et al., 2016). The use of smartphones for educational purposes (mobile learning) can enable a favorable environment for the construction and fixation of learning, which has generated an increasing mobilization to investigate how to implement, validate and improve these tools for teaching anatomy (Rondon et al., 2013; Pather et al., 2020; Küçük et al., 2016; Lall et al., 2019; Egarter et al., 2020).

In this context of constant innovation, tools such as the game-based student response system (GSRS) emerge, a new generation of "clickers", instruments used to provide greater interaction between professors and students in the classroom (Caldwell, 2007; Wang, 2015). Kahoot! is a GSRS launched in 2013 that allows the creation of interactive multi-choice questionnaires, the result of the Lecture Quiz prototype developed by the Norwegian University of Science and Technology (Wang, 2015). It is a user-centered tool based on behavioral design methodologies (Plump and LaRosa, 2017). In this sense, it can be used to review knowledge, assess students continuously and improve classroom dynamics, in order to increase student motivation, pleasure and concentration (Wang and Tahir, 2020).

Our hypothesis is that the Kahoot! score may generate useful feedback for the student to measure whether the taught content has been assimilated at the end of the lecture. Therefore, the objective of this study is to investigate the relationship between the Kahoot! score and the performance obtained in the traditional examination of the anatomy subject, as well as understanding the students' perception of the use of Kahoot! in teaching anatomy, according to their sociodemographic profile.

\section{MATERIALS AND METHODS}

\section{Ethical Approval}

The study was approved by the Research Ethics Committee of the Federal University of Paraiba's Health Sciences Center, under protocol number 2.617.483. All ethical and legal aspects for research with human beings were adopted and the participants signed the Free and Informed Consent Term, according to Resolution $\mathrm{n}^{\circ}$ $466 / 2012$ of the Brazilian National Health Council.

\section{Study design}

This is a quantitative cross-sectional study, developed in the Department of Morphology of the Federal University of Paraiba's Health Sciences Center, by the Human Anatomy professors and teaching assistants of the Medicine course. This subject is part of the integrated curriculum of the pre-clinical phase, which consists of lectures with theoretical exposition of the content and practical activities with human cadavers in the anatomy laboratory. The course content is divided into 5 topics of systemic anatomy (TSA): TSA1 - Cardiovascular System (6 lectures); TSA2 - Respiratory System (4 lectures); TSA3 - Digestive System (8 lectures); TSA4 - Endocrine and Reproductive Systems (4 lectures); and TSA5 - Urinary System (2 lectures). The data collection was conducted in the first semester of 2018, when students were invited to respond Kahoot! quizzes about the content taught, at the end of the lectures. At the completion of every TSA, the students were sent to a traditional examination. In 
addition, an opinion questionnaire about Kahoot! platform was applied at the end of the course.

\section{Participants' recruitment}

Fifty-six first-year medical students enrolled in the Human Anatomy course were invited to participate in the study. The inclusion criteria adopted was to have participated in at least one Kahoot! quiz during the academic semester, and to have taken the traditional examination of this TSA. Fifty-three students (94.6\%) who met these criteria were included and the student participation in each TSA was considered independently, totalizing 190 observations. Twenty-one students (39.6\%) participated in the activities of all five TSAs; 9 (16.9\%) participated in the activities of four different TSAs; 10 (18.8\%) participated in the activities of three different TSAs; 6 (11.3\%) participated in the activities of two different TSAs; and 7 (13.2\%) participated in only one TSA. Thirty-nine (73.6\%) students responded to the socio-demographic profile questionnaire. The participants' median age was 20 years, ranging from 18 to 26 years. $54.7 \%$ were men, $56.4 \%$ lived in their own family home, 89.7\% were never employed, $97.4 \%$ were single and $97.4 \%$ had never attended another college before. Per capita family income was expressed in minimum wages (MW) in force at the time, with 1 MW equivalent to R $\$ 954.00$ or U\$261.40. The median of the per capita family income was 1.6 $\mathrm{MW}$, ranging from 0.3 to $6.0 \mathrm{MW}$.

\section{Kahoot! platform}

Two experienced anatomy professors produced and reviewed 16 Kahoot! quizzes, containing questions that reflected the learning objectives of the respective lectures (Graham, 2015). Each quiz was composed of 5 multiple-choice questions with 4 alternatives of which students should choose a correct alternative regarding a concept or anatomical structure described through a text or an image. The parameters "question timer" and "points possible" were adjusted to 60 seconds and 1000 points, respectively.

At the end of the lectures, a Kahoot! quiz was shown from a computer connected to a projector and interested students participated through the Kahoot! app for smartphones (Aktekin et al., 2018). The students were instructed on the operating rules of the platform and were asked to identify themselves by a previously defined numerical code to enable data tabulation and ensure anonymity. The platform was programmed to display the question and only then present the alternatives and start the timing.

A ranking with the best scores for the sum of the 5 questions is displayed after the completion of the quiz. The score for each answer is calculated using the formula [ (1 - ((\{response time\}/ \{question timer\}) / 2)) \{points possible\} 1 . The player can also receive 100, 200, 300 and 400 streak bonus points for 2, 3, 4 and 5 correct answers, respectively. Thus, the platform calculates the final score based on the number of correct answers and the speed with which the answers were given and, finally, provides a report of this data (Wang and Tahir, 2020). In every quiz applied, the maximum possible score was 6000 points.

The quizzes were given in $16(66.7 \%)$ of the 24 lectures scheduled in the Human Anatomy course. Indeed, 4, 1, 5, 4 and 2 Kahoot! were conducted in TSA1, TSA2, TSA3, TSA4 and TSA5, respectively, which provided a frequency of quizzes for these TSAs of $66.7 \%, 25 \%, 62.5 \%$, $100 \%$ and $100 \%$. Student participation in each TSA was represented by the arithmetic mean of Kahoot! score (MKS) in the respective topic.

\section{Traditional examination}

The official assessment of the students was carried out at the end of every TSA, totaling five tests. This traditional examination was composed of two parts, one theoretical and one for the identification of anatomical structures in cadavers. Every theoretical test included 10 multiple-choice questions compatible with the content taught. The identification test consisted of 20 anatomical elements discussed in the lecture. The student's grade in the traditional examination (GTE) of each TSA was represented by the arithmetic mean of the scores of the theoretical test and the identification test on anatomical structures in the cadaver, ranging from 0 to 10. GTE greater than or equal to 7, 8 and 9 were considered as sufficient, regular, and excellent performance, respectively. 


\section{Student feedback}

A questionnaire developed by the authors and based on the Likert scale was used to assess the students' opinions about the use of Kahoot!, considering the following sentences: 'I had fun using Kahoot!'; 'I would recommend Kahoot! to assist in learning of other subjects'; 'I would use Kahoot outside of the university'; 'Kahoot was important for me to learn anatomical terms taught in the lecture'; 'Kahoot! contributed to my performance in the Human Anatomy tests'; and 'Kahoot! was important to keep me motivated in the study of Human Anatomy'.

\section{Statistical analysis}

The statistical analysis was performed using $\mathrm{R}$ version 3.6.3 (R Core Team, Vienna, Austria) and RStudio version 1.2.5033 (RStudio Inc., Boston, MA, USA). The internal consistency of the opinion questionnaire was evaluated by Cronbach's alpha coefficient. The data normality was verified by the Kolmogorov-Smirnov test with Lilliefors adjustment. Due to the non-parametric distribution, the Kruskal-Wallis test was used to assess whether there was a variation in MKS and GTE between the different TSAs. Spearman's correlation coefficient was calculated to assess whether there is an association between MKS and GTE. Area under the ROC curve (AUC) was used to evaluate the performance of MKS in predicting GTE (score greater than or equal to 7, 8 and 9). The parameters sensitivity, specificity, positive predictive value, negative predictive value, and accuracy were also calculated using as MKS cutoff point $\geq 3000$. The Chi-square test was used to assess the association between MKS in categories and the student's performance in the traditional examination, as well as to identify the association between sociodemographic variables and the students' opinion about the use of Kahoot!. All tests were applied considering a 95\% confidence interval.

\section{RESULTS}

\section{Relationship between Kahoot! score and the grade in the traditional examination}

Both MKS and GTE varied according to TSA ( $p<0.001$ ), and, except for TSA2, these scores increased as the subject progressed. Detailed descriptive statistics are shown in Table 1. There was a significant positive and moderate

Table 1. Descriptive analysis of the Kahoot! score and grade in the traditional examination according to the topics of systemic anatomy course $(\mathrm{n}=190)$.

\begin{tabular}{|c|c|c|c|c|c|c|c|c|c|}
\hline Parameter & TSA & $\mathbf{n}$ & Minimum & Maximum & Mean & SD & Median & IQR & Normality \\
\hline \multirow{6}{*}{ MKS } & 1 & 48 & 843.0 & 4721.8 & 2354.5 & 827.5 & 2348.1 & 1173.5 & 0.200 \\
\hline & 2 & 34 & 775.0 & 4355.0 & 2158.4 & 997.1 & 1796.0 & 1308.0 & 0.020 \\
\hline & 3 & 41 & 1721.0 & 5146.5 & 3344.7 & 828.2 & 3470.5 & 1217.8 & 0.200 \\
\hline & 4 & 39 & 932.0 & 4999.3 & 3578.7 & 890.2 & 3680.0 & 1077.5 & 0.200 \\
\hline & 5 & 28 & 969.0 & 5601.5 & 3643.1 & 1382.9 & 3916.0 & 2484.1 & 0.200 \\
\hline & Total & 190 & 775.0 & 5601.5 & 2974.3 & 1144.7 & 2950.8 & 1690.3 & 0.200 \\
\hline \multirow{6}{*}{ GTE } & 1 & 48 & 3.9 & 10.0 & 8.2 & 1.2 & 8.2 & 1.4 & 0.200 \\
\hline & 2 & 34 & 3.5 & 9.3 & 7.6 & 1.4 & 7.9 & 1.7 & 0.040 \\
\hline & 3 & 41 & 3.9 & 10.0 & 8.5 & 1.4 & 9.1 & 1.8 & 0.004 \\
\hline & 4 & 39 & 4.3 & 10.0 & 8.8 & 1.4 & 9.3 & 1.4 & $<0.001$ \\
\hline & 5 & 28 & 8.5 & 10.0 & 9.6 & 0.4 & 9.8 & 0.5 & $<0.001$ \\
\hline & Total & 190 & 3.5 & 10.0 & 8.5 & 1.4 & 8.8 & 1.6 & $<0.001$ \\
\hline
\end{tabular}

TSA = topic of systemic anatomy; SD = Standard deviation; IQR = interquartile range; MKS = Mean of Kahoot! score; GTE = grade in the traditional examination 
correlation between MKS and GTE (rho $=0.43$, $\mathrm{p}<0.001)$. MKS showed regular performance to predict GTE $\geq 8$ (AUC $=0.720, \mathrm{p}<0.001)$ and GTE $\geq 9$ (AUC $=0.734, p=0.037)$, but performance was poor to predict GTE $\geq 7$ (AUC $=0.655, p=0.018$ ), as shown in Fig. 1. The cut-off point MKS $\geq 3000$ (half of the maximum possible score to be reached) was chosen to perform a detailed analysis, as shown in Table 2.

Considering the categories MKS $<3000$ and MKS $\geq 3000$, there was a significant association between the Kahoot! score and performance in the traditional examination (Fig. 2). A total of $94.4 \%$ of students in the MKS $\geq 3000$ group achieved GTE $\geq$ 7, which was statistically different from the $83.0 \%$ of students who achieved this grade in the MKS < 3000 group ( $p=0.014$ ). While $85.6 \%$ of students in the MKS $\geq 3000$ group reached GTE $\geq 8$, this percentage was $61.0 \%$ in the MKS $<3000$ group $(\mathrm{p}<0.001)$. Finally, $67.8 \%$ of students in the MKS $\geq$
3000 group achieved GTE $\geq 9$, versus only $28.0 \%$ in the MKS $<3000$ group ( $<<0.001)$.

\section{Student opinion about Kahoot!}

Thirty-nine participants (73.6\%) answered the opinion questionnaire. The questionnaire showed substantial internal consistency, with Cronbach's Alpha of 0.799. The level of agreement of the participants with the sentences is shown in Fig. 3. It was found that $83.3 \%$ of younger students, up to 19 years old, agreed that the use of Kahoot! was important in motivating the study of Human Anatomy, versus $52.4 \%$ in the group aged 20 or over $(p=0.041)$. There was no association between the students' opinion about the use of Kahoot! and other sociodemographic variables analyzed (gender, paid employment, marital status, previous education, housing type and family income per capita).

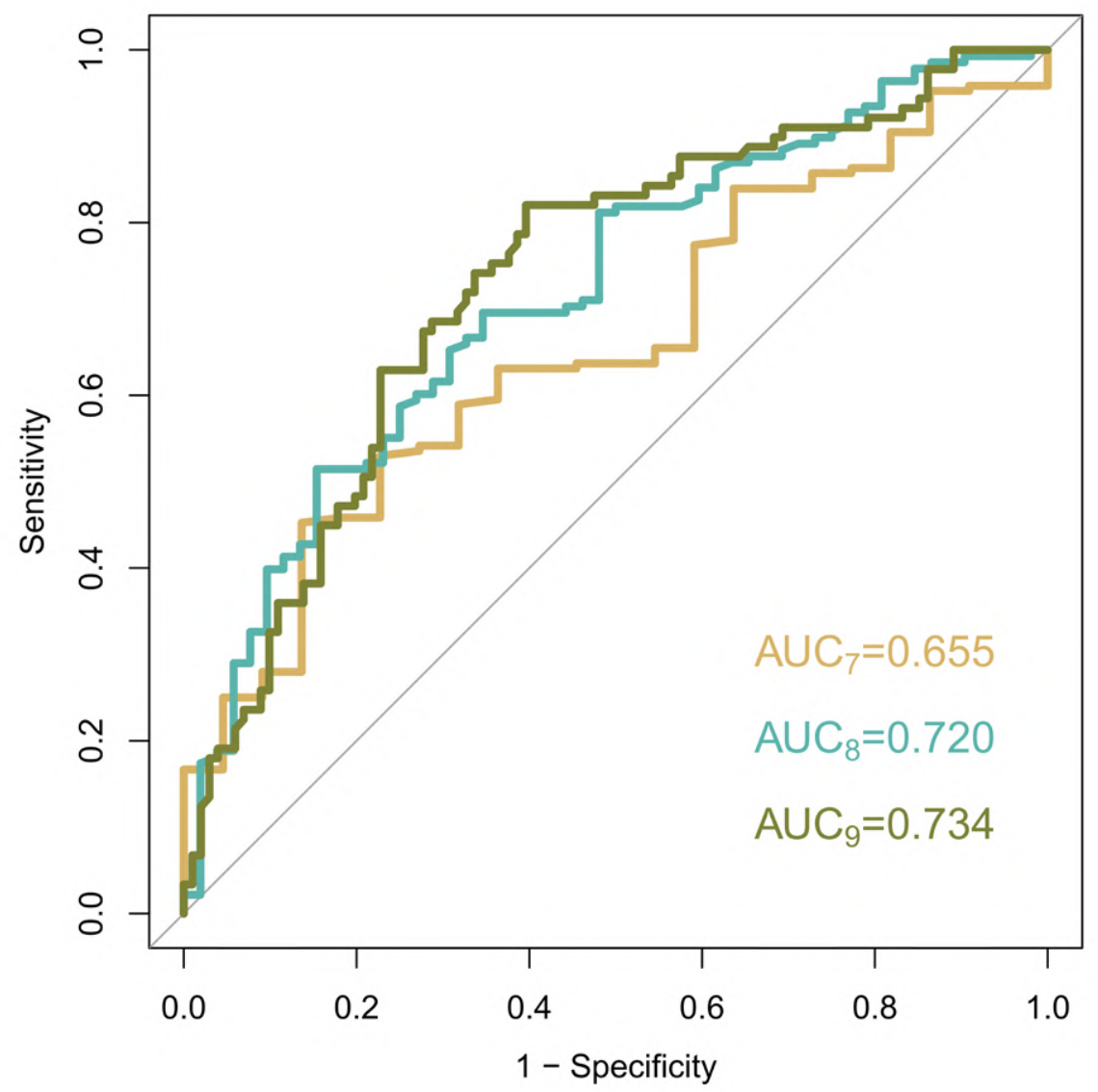

Fig. 1.- ROC curve using the Kahoot score as a predictor of grade in the traditional examinations $(\mathrm{n}=190)$. 
Table 2. Diagnostic test results to evaluate the ability of Kahoot! score (MKS) greater than or equal to 3000 to predict grade in the traditional examination (GTE) greater than or equal to 7, 8 and $9(\mathrm{n}=190)$.

\begin{tabular}{|c|c|c|c|c|c|c|}
\hline \multirow{2}{*}{$\begin{array}{l}\text { MKS } \geq 3000 \\
\text { Diagnostic tests }\end{array}$} & \multicolumn{2}{|c|}{ GTE $\geq 7.0$} & \multicolumn{2}{|c|}{ GTE $\geq 8.0$} & \multicolumn{2}{|c|}{ GTE $\geq 9.0$} \\
\hline & $(\%)$ & $95 \% \mathrm{CI}$ & $(\%)$ & $95 \% \mathrm{CI}$ & $(\%)$ & $95 \% \mathrm{CI}$ \\
\hline Sensitivity & 50.6 & $43.0-58.2$ & 55.8 & $47.5-64.1$ & 68.5 & $58.9-78.2$ \\
\hline Specificity & 77.3 & $59.8-94.8$ & 75.0 & $63.2-86.8$ & 71.3 & $62.5-80.1$ \\
\hline Positive predictive value & 94.4 & $89.7-99.2$ & 85.6 & $78.3-92.8$ & 67.8 & $58.1-77.4$ \\
\hline Negative predictive value & 17.0 & $9.6-24.4$ & 39.0 & $29.4-48.6$ & 72.0 & $63.2-80.8$ \\
\hline Accuracy & 53.7 & $46.6-60.8$ & 61.1 & $54.1-68.0$ & 70.0 & $63.5-76.5$ \\
\hline
\end{tabular}
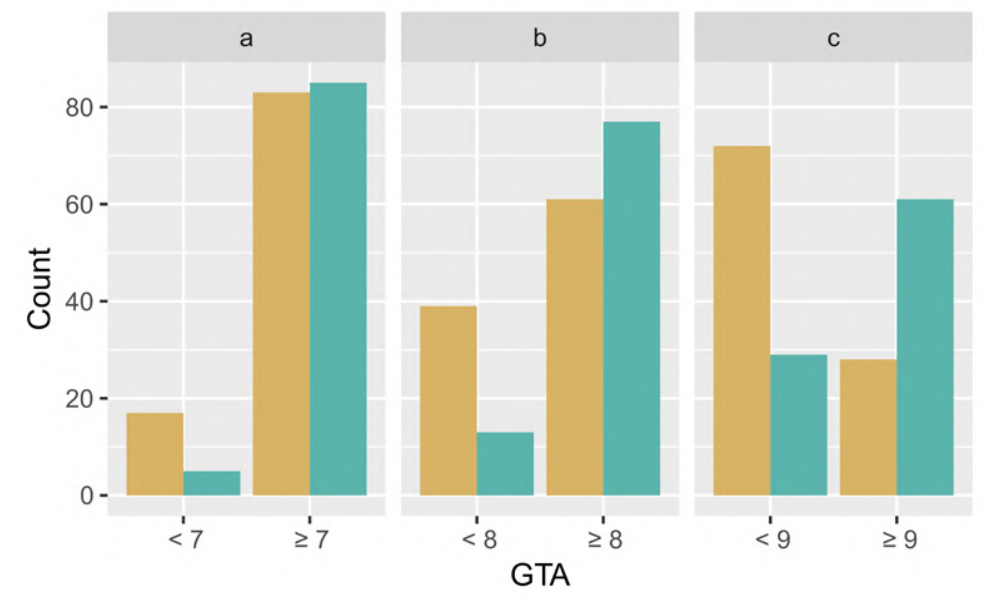

MKS

Fig. 2.- Distribution of the frequency of grades in the traditional examination (GTE) greater than or equal to 7 (a), 8 (b) and 9 (c), according to the mean Kahoot! score (MKS) ( $\mathrm{n}=190)$.

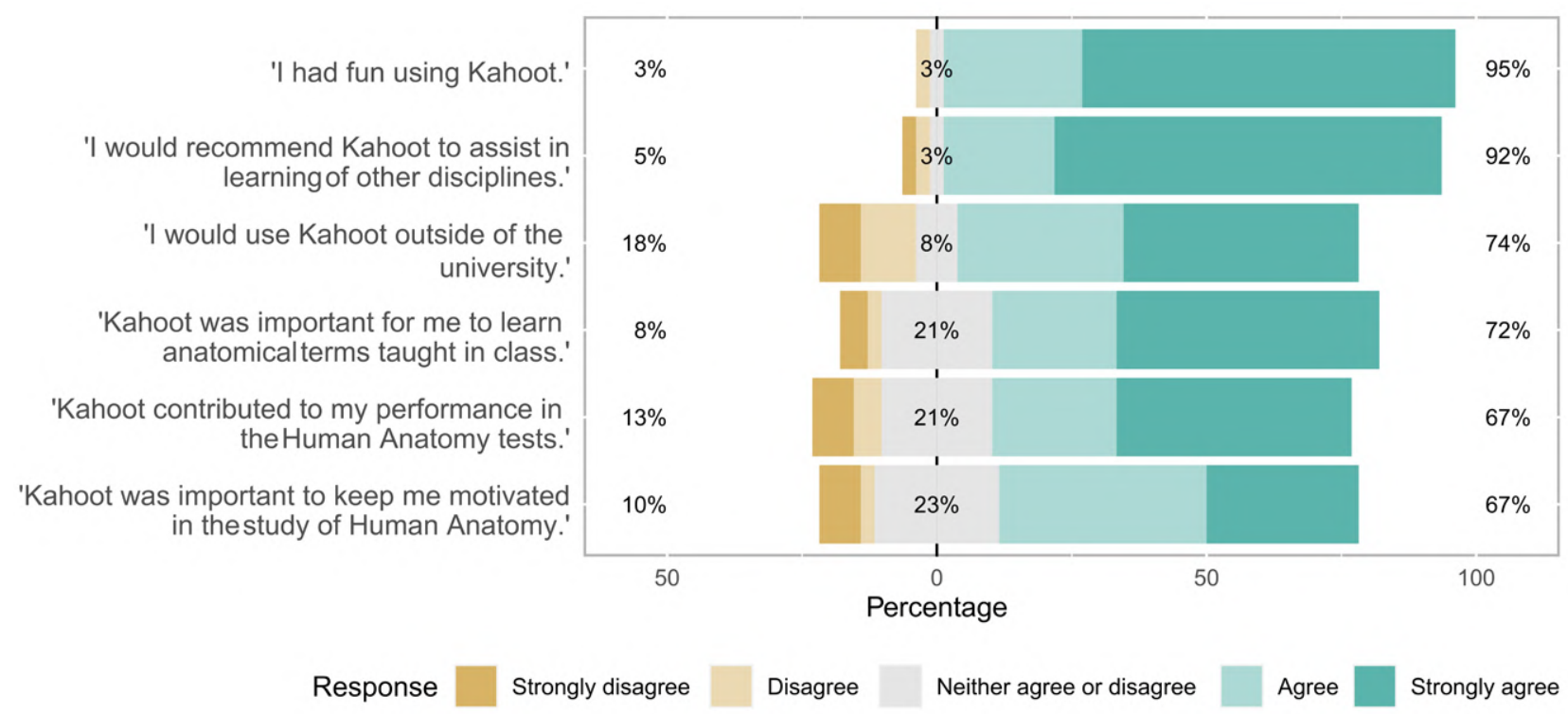

Fig. 3.- Student's opinion about the use of Kahoot! in the study of Human Anatomy, considering the level of agreement with the sentences ( $\mathrm{n}=39$ ). 


\section{DISCUSSION}

Kahoot! has gained prominence in the context of game-based learning (Wang, 2015; Plump and LaRosa, 2017; Wang and Tahir, 2020). This study raises the hypothesis that the Kahoot! can generate useful feedback for the student to measure the assimilation of the content taught in the lecture. This led us to investigate whether there is a relationship between the Kahoot! score and the grade in the traditional examination, as well as understanding the students' perception of the platform according to the sociodemographic characteristics. Our data shows that the performance in Kahoot! was associated with performance in the traditional examination. In addition, students were receptive to using Kahoot! in the classroom and the motivation was correlated with their age.

The parameters MKS and GTE varied in a peculiar way during the Human Anatomy course. Except for TSA2, the mean and median of MKS and GTE increased as the subject progressed, and this may be associated with the participants' natural adaptation process to Kahoot! quiz format and traditional examination throughout the course. The characteristics of TSA2 may have triggered the measurement of a smaller MKS, because in this topic the MKS represents the application of a single quiz, with non-normal distribution and low number of participants. Knowing that the TSA2 GTE was also lower compared to the others, it is possible that both scores are actually reflecting less knowledge retention in the short and medium term in that specific TSA, due to factors not controlled in this study. The correlation between MKS and GTE has already been identified in previous studies, as in a study that evaluated Kahoot! as a method to review concepts at the end of the course (Dell and Chudow, 2019). Our study is a pioneer in proposing the application of Kahoot! at the end of each lecture, in order to compare the MKS and GTE across the various topics in the course. The correlation found in this study indicates that MKS can be used as a predictor of good performance in the subject of Human Anatomy.

The ROC curve with the best AUC was the one that used score 9 as a goal in the traditional examination. This was because the overall performance of the students was high (general median of 8.8), which means that $50 \%$ of the students achieved performance in the traditional examination above 8.8. As for grade 7 in the traditional examination, the minimum parameter for approval in the subject, there was a low AUC. This may be related to the different aspects really evaluated by Kahoot! and by traditional examination, since the cognitive levels of the educational objectives of both tests were not fully equivalent. While the questions elaborated for Kahoot! involved the dimensions of the cognitive process of levels 1 (remember) and 2 (understand), the traditional examination presented questions where the student should be able to perform applications (level 3), analyses (level 4) and examinations (level 5) (Krathwohl, 2002). Thus, it was expected that it would not be completely possible to demonstrate a strong correlation between the two examination methods.

Although the global analysis of the ROC curves shows low accuracy, when considering the predictive values, interpretation from the individual aspect can be important for each student. Those with MKS $\geq 3000$ had a 94.4\%, $85.6 \%$ and $67.8 \%$ probability of obtaining a grade equal to or greater than 7, 8 and 9, respectively, according to the positive predictive value found. When it comes to the subject pass parameter (GTE $\geq 7$ ), obtaining MKS $<3000$ revealed a very low negative predictive value (17.0\%), i.e., even reaching a low Kahoot! score, the student can perform well in the traditional examination. This is justified because Kahoot! evaluates the moment immediately after the lecture. The association between the categorized MKS and GTE values highlights that Kahoot! can serve as an alert for students with low MKS, demonstrating that more dedication may be needed to study the respective content for traditional summative examination.

The use of Kahoot! in the classroom can contribute to motivation, focus on the most relevant concepts and reflection on what has been assimilated (Ismail et al., 2019; Licorish et al., 2018; Ismail and Mohammad, 2017). Apart from successful prior use, the main reason for choosing the Kahoot! platform as a GSRS was to 
keep students simultaneously focused on the same question and then discuss the answers together. Other advantages were the user-friendly interface of the platform, the possibility to add media of different formats and the quickness to apply the quiz. Furthermore, the Kahoot! quiz provides the learner with real-time feedback and does not require prior training to be implemented. The number of questions in each Kahoot! quiz was adequate for the objectives of the lecture and for the time dedicated to the execution of the activity. The sections ranged from 10 to 15 minutes, including students' connection time to the Kahoot! application, reading, answering, discussing each question, viewing the score on each question, and the final podium, which was compatible with the limited time available for teaching Human Anatomy.

Systematic reviews show moderate evidence of the effect of game-based learning on students' overall performance (Gorbanev et al., 2018; All et al., 2016; Abdulmajed et al., 2015). Specifically, Kahoot! has been associated with positive effects on learning performance and classroom dynamics, although there are studies that indicate little or no effect (Wang and Tahir, 2020; Sumanasekera et al., 2020). Our results demonstrate good feedback from students on Kahoot!, which in itself would justify its use as a complementary method. It is interesting to note that the participants have fun with Kahoot! and would indicate it in other subjects. However, there was less agreement on the importance of Kahoot! for content fixing, motivation, and final performance, which maintains that students understand Kahoot! as a method that improves classroom dynamics but has less influence on their learning process. Regarding the age group, it is known that age is a factor that influences the receptivity to the use of applications and online platforms as a pedagogical practice (Fan et al., 2016). Our results show that the motivation for the study linked to the emotional connection generated by using the Kahoot! platform has suffered from age factor, being more intense among younger individuals.

Finally, Kahoot! presents some peculiarities from the pedagogical point of view. In fact, game-based learning is not restricted to a specific learning theory and uses elements of constructivism, humanism, cognitivism and behaviorism (Wu et al., 2012). Kahoot! sessions bring aspects of stimulus and reinforcement seen in behaviorism, through the typical dynamics of games, but there is no aspect of repetition of behavior to generate learning. The game sessions involve humanistic characteristics such as trust, freedom to participate and student self-knowledge, however the pace is not determined by the student. Thus, the authors consider that the most striking principles of Kahoot! sessions are related to constructivist cognitivism, since students are challenged, and given the difficulties of assimilation by the professor's proposal, they undergo a process of modification, adaptation, and restoration of balance. Therefore, the student adapts to the process, and is educated to learn.

\section{Limitations}

This study has several limitations. First, the sample was restricted to students of only one course, which prevented the presentation of reproducibility of results in another group. Second, there was no rigor regarding the participation of the students in the Kahoot! sessions. This may have contributed to a greater participation of those who liked the subject and eventually had better results, as it was a voluntary activity that required the student to remain in the classroom for a longer period. The use of codes to maintain the anonymity of students was an alternative employed to minimize the lack of adherence by the fear of exposure. Thirdly, there were also technical limitations regarding the applicability of the method, such as the need for the student to have smartphone and internet access at the time of the quiz. It was therefore not uncommon for some students to just attend the sessions without participating in the game. Furthermore, the demand for digital resources such as a computer and an image projector or TV was also a limiting factor, especially in the TSA2, as most classes on this topic were taught in the anatomy laboratory. The lack of these devices in the laboratory prevented the application of 
Kahoot! at the end of some of the lectures. Lastly, the quality of internet access may also have been a source of bias in the quiz result, as Kahoot! counts the response time to generate the score obtained, which may have benefited students that had a smartphone with a better processor and internet data provider.

\section{CONCLUSION}

The performance in the Kahoot! quiz is associated with performance in the traditional examination, which can provide the student with immediate feedback on the retention of the exposed content, and can serve as a predictor of final performance, although the two processes have differences in the dimension of the assessed cognitive process. Students understand that this instrument makes classroom dynamics more interactive and assists in content fixation, motivation, and academic performance. The motivation generated using technologies such as the Kahoot! platform in the classroom can be influenced by the age of students.

\section{REFERENCES}

ABDULMAJED H, PARK YS, TEKIAN A (2015) Assessment of educational games for health professions: A systematic review of trends and outcomes. Med Teach, 37(S1): S27-S32.

AKTEKIN NÇ, ÇELEBI H, AKTEKIN M (2018) Let's kahoot! Anatomy. Int J Morphol, 36(2): 716-721.

ALL A, CASTELLAR EPN, LOOY JV (2016) Assessing the effectiveness of digital game-based learning: Best practices. Comput Educ, 92: 90-103.

CALDWELL JE (2007) Clickers in the large classroom: Current research and best-practice tips. CBE Life Sci Educ, 6(1) :9-20.

DELL KA, CHUDOW MB (2019) A web-based review game as a measure of overall course knowledge in pharmacotherapeutics. Curr Pharm Teach Learn, 11(8): 838-842.

EGARTER S, MUTSCHLER A, TEKIAN A, NORCINI J, BRASS K (2020) Medical assessment in the age of digitalisation. BMC Med Educ, 20(1): 101.

ESTAI M, BUNT S (2016) Best teaching practices in anatomy education: A critical review. Ann Anat, 208: 151-157.

FAN S, RADFORD J, FABIAN D (2016) A mixed-method research to investigate the adoption of mobile devices and Web2.0 technologies among medical students and educators. BMC Med Inform Decis Mak, 16(1): 43.

GORBANEV I, AGUDELO-LONDOÑO S, GONZÁLEZ RA, CORTES A, POMARES A, DELGADILLO V, YEPES FJ, MUÑOZ Ó (2018) A systematic review of serious games in medical education: quality of evidence and pedagogical strategy. Med Educ Online, 23(1): 1-9.

GRAHAM K (2015) TechMatters: Getting into Kahoot!(s): Exploring a game-based learning system to enhance student learning. Loex $Q$, 42(3): 6-7.
GUIMARÃES B, DOURADO L, TSISAR S, DINIZ JM, MADEIRA MD, FERREIRA MA (2017) Repensar a anatomia: Como superar os desafios da evolução da educação médica. Acta Med Port, 30(2): 134-140.

ISMAIL MAA, AHMAD A, MOHAMMAD JAM, FAKRI NMRM, NOR MZM, PA MNM (2019) Using Kahoot! as a formative assessment tool in medical education: A phenomenological study. BMC Med Educ, 19(1): 230 .

ISMAIL MAA, MOHAMMAD JAM (2017) Kahoot: A promising tool for formative assessment in medical education. Educ Med J, 9(2): 19-26.

KRATHWOHL DR (2002) A revision of bloom's taxonomy: An overview. Theory Pract, 41(4): 212-218.

KÜÇÜK S, KAPAKIN S, GÖKTAŞ Y (2016) Learning anatomy via mobile augmented reality: Effects on achievement and cognitive load. Anat Sci Educ, 9(5): 411-421.

LALL P, REES R, YI LAW GC, DUNLEAVY G, COTIČ Ž, CAR J (2019) Influences on the implementation of mobile learning for medical and nursing education: Qualitative systematic review by the digital health education collaboration. J Med Internet Res, 21(2): e12895.

LICORISH SA, OWEN HE, DANIEL B, GEORGE JL (2018) Students perception of Kahoot!'s influence on teaching and learning. Res Pract Technol Enhanc Learn, 13(1): 1-23.

NIEDER GL, PARMELEE DX, STOLFI A, HUDES PD (2005) Teambased learning in a medical gross anatomy and embryology course. Clin Anat, 18(1): 56-63.

PATHER N, BLYTH P, CHAPMAN JA, DAYAL MR, FLACK NAMS, FOGG QA, GREEN RA, HULME AK, JOHNSON IP, MEYER AJ, MORLEY JW, SHORTLAND PJ, ŠTRKALJ G, ŠTRKALJ M, VALTER K, WEBB AL, WOODLEY SJ, LAZARUS MD (2020) Forced disruption of Anatomy Education in Australia and New Zealand: An acute response to the Covid-19 pandemic. Anat Sci Educ, 13(3): 284-300.

PAYNE KFB, WHARRAD H, WATTS K (2012) Smartphone and medical related App use among medical students and junior doctors in the United Kingdom (UK): A regional survey. BMC Med Inform Decis Mak, 12(1): 121.

PLUMP CM, LAROSA J (2017) Using Kahoot! in the classroom to create engagement and active learning: a game-based technology solution for eLearning novices. Manag Teach Rev, 2(2): 151-158.

RONDON S, SASSI FC, FURQUIM DE ANDRADE CR (2013) Computer game-based and traditional learning method: A comparison regarding students' knowledge retention. BMC Med Educ, 13(1): 30.

RUZYCKI SM, DESY JR, LACHMAN N, WOLANSKYJ-SPINNER AP (2019) Medical education for millennials: How anatomists are doing it right. Clin Anat, 32(1): 20-25.

SHAFFER K (2004) Teaching anatomy in the digital world. $N$ Engl $J$ Med, 351(13): 1279-1281.

SINGH K, BHARATHA A, SA B, ADAMS OP, MAJUMDER MAA (2019) Teaching anatomy using an active and engaging learning strategy. $B M C$ Med Educ, 19(1): 149.

SUMANASEKERA W, TURNER C, LY K, HOANG P, JENT T, SUMANASEKERA T (2020) Evaluation of multiple active learning strategies in a pharmacology course. Curr Pharm Teach Learn, 12(1): 8894.

TURNEY BW (2007) Anatomy in a modern medical curriculum. Ann R Coll Surg Engl, 89(2): 104-107.

WANG AI (2015) The wear out effect of a game-based student response system. Comput Educ, 82: 217-227.

WANG AI, TAHIR R (2020) The effect of using Kahoot! for learning - A literature review. Comput Educ, 149: 103818.

WILSON AB, NOTEBAERT AJ, SCHAEFER AF, MOXHAM BJ, STEPHENS S, MUELLER C, LAZARUS MD, KATRIKH AZ, BROOKS WS (2020) A look at the Anatomy Educator job market: anatomists remain in short supply. Anat Sci Educ, 13(1): 91-101. 
WU WH, HSIAO HC, WU PL, LIN CH, HUANG SH (2012) Investigating the learning-theory foundations of game-based learning: A metaanalysis. J Comput Assist Learn, 28(3): 265-279.

ZUMWALT AC, LUEFLER RS, MONTEIRO J, SHAFFER K (2010) Building the body: Active learning laboratories that emphasize practical aspects of anatomy and integration with radiology. Anat Sci Educ, 3(3): 134.140. 